\title{
Association of Intrarenal Resistance Index and Systemic Atherosclerosis After Kidney Transplantation.
}

\section{Philip Köger}

Faculty of Medicine Zurich

\section{Stephan Engelberger}

Vascular Center Cantonal Hospital Baden

\section{Rudolf Wüthrich}

University Hospital of Zurich

\section{Marie-Luise Valentin}

University Hospital of Zurich

\section{Nils Kucher}

University Hospital of Zurich

\section{Christoph Thalhammer}

Clinic for Angiology Cantonal Hospital Aargau

Robert Karl Clemens ( $\nabla$ robert.clemens@ksb.ch )

Vascular Center Cantonal Hospital Baden

\section{Research Article}

Keywords: Patients, kidney transplant, cardiovascular, atherosclerosis

Posted Date: April 12th, 2021

DOl: https://doi.org/10.21203/rs.3.rs-355379/v1

License: (c) (i) This work is licensed under a Creative Commons Attribution 4.0 International License. Read Full License

Version of Record: A version of this preprint was published at In Vivo on January 1st, 2021. See the published version at https://doi.org/10.21873/invivo.12635. 


\section{Abstract \\ Background}

Patients after kidney transplant are at risk of cardiovascular morbidity. Surveillance of kidney transplants is mandatory to ensure a maximal transplant lifespan. Renal function is measured by levels of creatinine (clearance) while morphological aspects and other parameters like the kidney-size and Resistance Index are assessed with Duplex sonography. An elevated Resistance Index is associated with renal graft failure. The Resistance Index can also be measured in the carotid artery. It is uncertain whether a correlation between intrarenal RI after kidney transplant and the RI of the internal carotid artery exists.

\section{Material and Methods}

Resistance index of kidney transplants and of the carotid artery were measured with duplex sonography in adult patients after kidney transplant. Carotid intima-media thickness as well as the Framingham risk score and the Augmentation index, all known markers of atherosclerosis, were assessed. Statistical analysis was performed with STATA. Continuous data were expressed as means $+/$ - standard deviation and compared by Kruskal-Wallis Test. Correlations between the RI in Carotid artery and the RI of the kidney transplant were based on Spearmen test with the level of significance set at $p<0.05$.

\section{Results}

98 consecutive patients $(60 \%$ male, mean age of $48.7(+/-15.6))$ were included. Mean interval after transplantation was $27.5(+/-8.5)$ months and the mean serum creatinine was $308(+/-220.3) \mathrm{mmol} / \mathrm{L}$. The RI of the internal carotid artery and the renal transplant were significantly correlated $(p<0.05)$. A strong correlation between the RIs and the Augmentation Index (Alx) was found.

\section{Conclusion}

The RI of the kidney transplant is correlated with the RI of the carotid artery and to markers of general atherosclerosis. This observation may be helpful to identify patients after kidney transplant with higher risk for cardiovascular events.

\section{Background}

Kidney transplant is the most frequently performed organ transplant [1]. It is the treatment of choice in end stage renal disease and is ideally performed before initiation of hemodialysis [2]. It is also more costeffective than long-term dialysis [3]. Color-coded Doppler sonography (CCDS) is part of the postoperative surveillance [4]. The surveillance may start as early as during, but should be initiated immediately after transplant [5]. 
Besides the diagnosis of arterial or venous obstruction, the intrarenal vascular resistance, called Resistance Index (RI) is measured [6]. The RI has been a proven sensitive marker of graft dysfunction but is unspecific [7]. The RI of the kidney transplant adapts rapidly to the host [8]. An elevated RI of 0.80 (normal range $0.6-0.7$ ) or higher indicates an unfavorable prognosis of renal function as well as increased mortality [9]. There is a significant association between an increased RI and markers of generalized atherosclerosis such as the Framingham risk score (FRS), the Carotid Intima-MediaThickness (CIMT) and the Ankle-Brachial-Index (ABI) but not for renal function measured with the glomerular-filtration-rate (GFR) [10]. Krumme et al. could show that recipient age is associated with the RI [11]. The RI of the internal carotid artery is a functional parameter for the generalized atherosclerotic process and is correlating well with wall hypertrophy measured as CIMT as a morphologic correlation to atherosclerosis [12]. Gerhart et al. could show that indices of systemic atherosclerosis such as the Framingham risk score are superior to ultrasound resistance indices for prediction of allograft survival [13]. Augmentation index (Alx) is a parameter measured by pulse wave analysis (PWA) used as a surrogate measure of arterial stiffness and is a useful marker of cardiovascular events [14]. A correlation between the RI of renal transplants and the carotid artery as well as the RI of the transplant and IMT, AIX and FRS was never investigated, but could theoretically be used as a tool to identify patients after kidney transplant with higher risk for cardiovascular events.

\section{Material And Methods}

Patients after kidney transplant, that gave informed consent were consecutively included. The institutional committee on clinical investigation of the University Hospital Zurich and the cantonal ethic committee Zurich approved this prospective study. All patients gave informed consent to participate in the study and could withdraw from the study any time. Informed consent was obtained from all subjects. If subjects were under 18 , informed consent was obtained from a parent and/or legal guardian.

All methods were carried out in accordance with relevant guidelines and regulations according to the ethics committee and the Declaration of Helsinki. The study is registered under NCT01001065 at ClinicalTrials.gov.

Exclusion criteria was the presence of any carotid or renal artery stenosis. Baseline values (including creatinine and creatinine that were used to estimate the GFR using the CKD-EPI Creatinine Eq. (2009)) were extracted from the patient chart [15].

Colour-coded duplex sonography (CCDS) and spectral analysis

Recognizing pathological findings like stenosis or arterio-venous fistulas becomes considerably easier with CCDS. To demonstrate non-perfused areas, application of a signal enhancer (contrast agent) may be particularly useful $[16,17]$. Various causes of an elevated RI value are displayed in Table 1. 
Table 1

Possible causes of an elevated resistance index

(adapted from Thalhammer C. [18]).

\begin{tabular}{|ll|}
\hline Renal & Extrarenal \\
\hline Acute rejection & Bradycardia \\
\hline Chronic rejection & Acute/chronic hydronephrosis \\
\hline Renal vein thrombosis & Cyclosporine toxicity \\
\hline Acute tubular necrosis & Hematoma, lymphocele \\
\hline Pyelonephritis & Compression by transducer \\
\hline Glomerulonephritis & Hypotension \\
\hline
\end{tabular}

Ultrasound was performed with the ultrasound system iU22 (Philips, Best, Netherlands), a high-resolution ultrasound with integrated software (QLAB). Board certified investigators according to a standardized protocol performed all CCDS. Three representative IMT measurements (QLAB) were bilaterally performed in the wall of the common carotid arteries at defined sites. These six intima-media thickness readings were averaged to give the mean common carotid IMT.

For the assessment of arterial stiffness using the augmentation index (Alx) radial artery pulse wave analysis was performed noninvasively with the SphygmoCor system (AtCor Medical; Sydney, Australia) by a single observer with patients in supine position. Augmented pressure was defined as the difference between the second and the first systolic peak, and Alx was expressed as percentage of the pulse pressure (difference between systolic and diastolic pressure).

A standardized questionnaire was used to compute the Framingham Risk score using the following data: smoking status, record a history of smoking, cholesterol levels, blood pressure, medication for arterial hypertension, diabetes, a family history of premature-onset cardiovascular disease (defined as myocardial infarction or stroke before the age of 65 in first-degree relatives), and current drug intake. The Framingham risk score was calculated for all patients at the webpage of the National Heart, Lung and Blood Institute website (http://www.nhlbi.nih.gov/guidelines/cholesterol/).

Data management and statistical analysis was performed with STATA software (StataCorp. 2019. Stata Statistical Software: Release 16. College Station, TX: StataCorp LLC). As the data is not normally distributed but monotonically related; we did not use Pearson correlation - Spearman does not carry assumptions about the distribution of the data. Unless indicated otherwise, continuous data are expressed as means +/- standard deviation, and compared by Kruskal-Wallis Test. To analyze the association of renal transplant resistance index with various indicators we categorized data firstly in tertiles where possible. Subsequently we compared mean RI of kidney transplant with the tertiles with Kruskal-Wallis test. Correlations between the RI in carotid artery and the RI of the kidney transplant were based on Spearmen test with the level of significance set at $p<0.05$. 


\section{Results}

98 patients (60\% male, $40 \%$ female) were consecutively evaluated between September 2009 and September 2015 and included in this prospective study. The mean interval after transplantation was 27.5 months $(+/-8.5)$ months and the mean age $(48.7+/-15.6)$ years. Patients were included regardless of their creatinine levels. The mean serum creatinine was $308 \mu \mathrm{mol} / \mathrm{l}(+/-220.3)$. Twenty-eight $(28.6 \%)$ patients were active smokers, 72 patients $(73.5 \%)$ were under antihypertensive medication. Baseline characteristics are presented in Table 2.

Table 2

Baseline characteristics

\begin{tabular}{|ll|}
\hline & Mean (SD) \\
\hline Age, years & $48.7( \pm 15.6)$ \\
\hline Female, male \% & 40,60 \\
\hline Months after kidney transplant & $27.5(+/-8.5)$ \\
\hline GFR ml/min & $29.2( \pm 19.6)$ \\
\hline Creatinine umol/l & $308.0( \pm 220.3)$ \\
\hline Cholesterol g/dl & $4.8( \pm 0.9)$ \\
\hline High density lipoprotein g/dl & $1.2( \pm 0.32)$ \\
\hline Systolic blood pressure $\mathrm{mmHg}$ & $137.4( \pm 18.0)$ \\
\hline Diastolic blood pressure $\mathrm{mmHg}$ & $78.7( \pm 12.1)$ \\
\hline FRS\%10J & $8.2( \pm 10.5)$ \\
\hline Abbreviations: SD: Standard deviation. FRS: Framingham risk score. \\
\hline
\end{tabular}

$\mathrm{RI}$ of the carotid artery and in the kidney transplant were statistically significantly correlated with a coefficient of 0.69 and a p-value $<0.05$ as shown in Fig. 1.

There was also a significant correlation of the RIs with the augmentation Index (AIX) with a coefficient of $0.43(p<0.05)$ and the CIMT with a correlation coefficient of $0.58(p<0.05)$ as shown in Table 3. 
Table 3

Spearman's ranked correlation of NTX RI and various indicators

\begin{tabular}{|llll|}
\hline & correlation coefficient & p-value & number of observations \\
\hline Creatinine & -0.04 & 0.67 & 98 \\
\hline GFR & 0.00 & 0.99 & 98 \\
\hline IMT carotid mean & 0.58 & $<0.05$ & 98 \\
\hline Alx & 0.43 & $<0.05$ & 47 \\
\hline Abbreviations: GFR: glomerular filtration rate. IMT: Intima-media thickness. Alx: Augmentation index. \\
\hline
\end{tabular}

Calculations based on Spearman Test did not show a correlation with renal function and RI. Only patients with a low FRS had a significant correlation with the transplant RI with a coefficient of $0.38(p<0.05)$ as shown in Table 4. 
Table 4

Association of RI (NTX mean) with various indicators

\begin{tabular}{|c|c|c|c|c|}
\hline Age* $^{*}$ & $15-42$ & $43-57$ & $58-76$ & Kruskal Wallis \\
\hline RI NTX mean & $0.62 \pm 0.06$ & $0.68 \pm 0.06$ & $0.75 \pm 0.06$ & \\
\hline Correlation coefficient & 0.24 & 0.33 & -0.06 & Chi $^{2}: 43.00$ \\
\hline $\mathrm{p}$-value & 0.18 & 0.06 & 0.76 & p-value: $<0.05$ \\
\hline GFR* & $5-12$ & $13-40$ & $42-60$ & \\
\hline RI NTX mean & $0.68 \pm 0.07$ & $0.68 \pm 0.08$ & $0.68 \pm 0.08$ & \\
\hline Correlation coefficient & -0.12 & -0.19 & -0.01 & Chi $^{2}: 43.00$ \\
\hline$p$-value & 0.48 & 0.33 & 0.94 & p-value: 0.57 \\
\hline Creatinine* & $56-157$ & $158-390$ & $398-987$ & \\
\hline RI NTX mean & $0.69 \pm 0.08$ & $0.69 \pm 0.08$ & $0.67 \pm 0.07$ & \\
\hline Correlation coefficient & 0.08 & 0.18 & 0.25 & 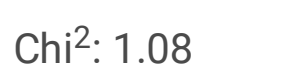 \\
\hline$p$-value & 0.65 & 0.31 & 0.17 & p-value: 0.58 \\
\hline Cholesterin* & $2.7-4.4$ & $4.5-5.2$ & $5.3-7.6$ & \\
\hline RI NTX mean & $0.70 \pm 0.09$ & $0.67 \pm 0.07$ & $0.67 \pm 0.08$ & \\
\hline Correlation coefficient & -0.18 & -0.11 & 0.26 & Chi²: 1.71 \\
\hline$p$-value & 0.32 & 0.50 & 0.19 & p-value: 0.42 \\
\hline HDL Cholesterin* & $0.62-1.06$ & $1.07-1.27$ & $1.29-2.37$ & \\
\hline RI NTX mean & $0.69 \pm 0.08$ & $0.67 \pm 0.08$ & $0.69 \pm 0.08$ & \\
\hline Correlation coefficient & -0.23 & -0.17 & -0.11 & $\mathrm{Chi}^{2}: 1.78$ \\
\hline$p$-value & 0.19 & 0.37 & 0.55 & p-value: 0.41 \\
\hline Framingham score & $<20$ & $20-30$ & $>30$ & \\
\hline RI NTX mean & $0.68 \pm 0.08$ & $0.74 \pm 0.06$ & $0.68 \pm 0.09$ & \\
\hline Correlation coefficient & 0.38 & -0.32 & -0.50 & $\mathrm{Chi}^{2}: 5.56$ \\
\hline$p$-value & $<0.05$ & 0.48 & 0.67 & p-value: 0.06 \\
\hline \multicolumn{5}{|c|}{$\begin{array}{l}\text { Note: For indicators marked with *, the analyzed categories are based on tertiles. Correlations and } \\
\text { their significance were computed using Spearman's rank correlation. }\end{array}$} \\
\hline
\end{tabular}




\begin{tabular}{|lllll|}
\hline Age* & $\mathbf{1 5 - 4 2}$ & $\mathbf{4 3 - 5 7}$ & $\mathbf{5 8 - 7 6}$ & Kruskal Wallis \\
\hline Smoking & Non-smoker & Smoker & \\
\hline RI NTX mean & $0.68 \pm 0.08$ & $0.67 \pm 0.08$ & \\
\hline Correlation coefficient & $\mathrm{n} / \mathrm{a}$ & -0.11 & $\mathrm{Chi}^{2}: 0.63$ \\
\hline p-value & 0.30 & 0.56 & $\mathrm{p}$-value: 0.43 \\
\hline $\begin{array}{l}\text { Note: For indicators marked with *, the analyzed categories are based on tertiles. Correlations and } \\
\text { their significance were computed using Spearman's rank correlation. }\end{array}$ & \\
\hline $\begin{array}{l}\text { Abbreviations: Rl: Resistance Index. NTX: kidney transplant. GFR: Glomerular Filtration Index. HDL: } \\
\text { High Density Lipoprotein. }\end{array}$ & & \\
\hline
\end{tabular}

\section{Discussion}

Patients after kidney transplant have an elevated risk for cardiovascular events. Risk stratification depends on markers of cardiovascular events. Intrarenal RI is a routinely assessed complex parameter that reflects the arterial compliance and pulsatility rather than renal vascular resistance [19]. The function of the allograft is as well routinely assessed with CCDS including the RI [20, 21]. Päivärinta et al. assessed the kidney function with PET-CT and RI measurements with CCDS to show that the RI was correlated with perfusion and fibrosis of the transplants [22]. Boran et al. found an association between recipients with proteinuria $<1000 \mathrm{mg} / 24 \mathrm{~h}$, and elevated Rls [23]. Radermacher et al. showed that an elevated RI was a strong predictor of allograft loss [9], but there is an ongoing discussion if the RI was sensitive and specific enough to discriminate between the different causes for acute graft failure [24]. In our population of 98 adult patients with previous kidney transplant we found a significant correlation between the mean kidney transplant RI and mean internal carotid artery RI with a correlation coefficient of 0.69 ( $p$-value $<0.05$ ).

Measurement of flow in the graft vessels and of the measurements of the RI help to exclude early thrombotic complications [7]. Further there is evidence that the RI obtained during the first 6 months after transplant failed to predict kidney allograft failure, whereas the RI obtained 12-18 months after transplantation appeared to be a useful to predict long-term allograft outcomes [25]. Heine et al. found that the RI in renal transplants is associated with systemic atherosclerosis as well as subclinical atherosclerotic vessel damage and is therefore not only a marker of renal but of vascular damage. They also showed that markers of cardiovascular risk or systemic atherosclerosis are superior outcome predictors for cardiovascular events compared to renal RI [18, 26]. Heine et al. included 105 renal transplant recipients in their study and used the FRS, the intrarenal $\mathrm{RI}$, the pulsatility index (PI), the IMT, and $A B I$ to assess risk for cardiovascular events and subclinical systemic atherosclerosis in these recipients[10]. They concluded that the renal RI rather than a specific marker of renal dysfunction is a complex integration of different factors, including arterial compliance, arterial pulsatility and peripheral resistance. According to Heine et al., the RI is associated with traditional cardiovascular risk factors and 
with subclinical atherosclerosis. They proposed also, that the RI is not related to the GFR. For this reason we included patients regardless of the renal function as measured by GFR and also found, that the RI seems not to be related to the GFR. Heine et. Al (or others) did not asses the carotid RI in their work though. The carotid RI is technically easier to measure and could be also be measured by health care professionals, that are less well trained in more complex renal ultrasound exams. The pathophysiological aspects of the relationship between renal microcirculation and cardiovascular system were further described by di Nicolò and Granata [27]. Brennan and Lentine found this result (RI being associated with traditional cardiovascular risk factors and with subclinical atherosclerosis) also in their cohort of patients with kidney transplants. They also used blood samples to measure (amongst others) inflammatory markers. Cardiovascular risk factors and comorbidities were then assessed by a questionnaire. They also studied the risk of coronary heart disease by using the FRS. RI and PI were calculated by CCDS as well as IMT and ABI included in the study data [28]. The same parameters were used in our study but also the carotid RI was measured (Heine et al. suggested measurements in native non-renal organs) as well as the Alx. The above shown results are according to the results of Heine et al. and Brennan and Lentine and show that the $\mathrm{RI}$ is associated with traditional cardiovascular risk factors. Especially the AIX, that was not measured in the other studies, correlates with subclinical atherosclerosis. Alx is used to measure arterial stiffness as a sign of vascular compliance and was associated with elevated RI. This correlation between $\mathrm{RI}$ and changes in vascular compliance/resistance was also shown using an in vitro model [29].

We could also show that there is a positive association between mean kidney transplant RI and mean internal carotid artery RI. We could not show a positive correlation between renal function and RI as described in former studies [11,30]. Only patients with a low FRS had a significant correlation with the transplant RI in our cohort, while Heine et al. found that renal transplant recipients with a high cardiovascular risk had increased RIs. There was a significant correlation with CIMT in our study as a sign of elevated cardiovascular risk that was also found in the two above mentioned studies [10, 28]. As described by Heine et al. we also found no significant correlation between renal function and CIMT.

\section{Conclusion}

Traditional cardiovascular risk factors and markers of subclinical atherosclerosis are related to elevated Rls in renal transplants. As the renal RI is correlated with carotid RI it might be more a general parameter of vascular compliance rather than an exclusive marker of intrarenal resistance. This finding might facilitate the mitigation of the cardiovascular risk in patients with kidney transplants. The measurement of carotid RI is technically easier to perform and could therefore be used by a larger number of health associated personal.

\section{Declarations}

\section{Ethics approval and consent to participate:}


All patients gave informed consent to participate in the study and could withdraw from the study any time. Informed consent was obtained from all subjects. If subjects were under 18 , informed consent was obtained from a parent and/or legal guardian.

The institutional committee on clinical investigation of the University Hospital Zurich and the cantonal ethic committee Zurich approved this prospective study

Consent for publication-NA/Not Applicable.

\section{Availability of data and materials:}

The datasets used and/or analyzed during the current study available from the corresponding author on reasonable request.

\section{Competing interests:}

There are no competing interests.

\section{Funding statement:}

There was no funding for this study.

\section{Authors' contributions}

P.K. collected data, contributed to the data, wrote the paper and reviewed the paper. S.E. contributed to the data, analyzed the data, wrote the paper and reviewed the paper. R.W. took part in the study design, reviewed the results, contributed to the style and reviewed the paper. MLV collected data, contributed to the data, wrote the paper and reviewed the paper. NK took part in the study design, reviewed the results, contributed to the style and reviewed the paper. CT designed the study, collected data, contributed to the data, wrote the paper and reviewed the paper. RC designed the study, collected data, contributed to the data, wrote the paper and reviewed the paper. P.K. and S.E. contributed equally to be listed as first authors. All authors reviewed the manuscript.

\section{Acknokledgement}

We thank Elisabeth Beckmann, PhD, MsC, MA, BA for the statistical analysis, figures and tables and her support.

\section{References}

1. Axelrod DA, McCullough KP, Brewer ED, Becker BN, Segev DL, Rao PS: Kidney and pancreas transplantation in the United States, 1999-2008: the changing face of living donation. American journal of transplantation : official journal of the American Society of Transplantation and the American Society of Transplant Surgeons 2010, 10(4 Pt 2):987-1002. 
2. Joo KW, Shin SJ, Lee SH, Ha JW, Kim S, Kim YS: Preemptive transplantation and long-term outcome in living donor kidney transplantation, single-center experience. Transplantation proceedings 2007, 39(10):3061-3064.

3. Laupacis A, Keown P, Pus N, Krueger H, Ferguson B, Wong C, Muirhead N: A study of the quality of life and cost-utility of renal transplantation. Kidney international 1996, 50(1):235-242.

4. Li JC, Ji ZG, Cai S, Jiang YX, Dai Q, Zhang JX: Evaluation of severe transplant renal artery stenosis with Doppler sonography. J Clin Ultrasound 2005, 33(6):261-269.

5. Thalhammer C, Aschwanden M, Mayr M, Koller M, Steiger J, Jaeger KA: Duplex sonography after living donor kidney transplantation: new insights in the early postoperative phase. Ultraschall in der Medizin (Stuttgart, Germany : 1980) 2006, 27(2):141-145.

6. Friedewald SM, Molmenti EP, Friedewald JJ, Dejong MR, Hamper UM: Vascular and nonvascular complications of renal transplants: sonographic evaluation and correlation with other imaging modalities, surgery, and pathology. J Clin Ultrasound 2005, 33(3):127-139.

7. Chudek J, Kolonko A, Król R, Ziaja J, Cierpka L, Wiecek A: The intrarenal vascular resistance parameters measured by duplex Doppler ultrasound shortly after kidney transplantation in patients with immediate, slow, and delayed graft function. Transplantation proceedings 2006, 38(1):42-45.

8. Aschwanden M, Mayr M, Imfeld S, Steiger J, Jaeger KA, Thalhammer C: Rapid adaptation of the intrarenal resistance index after living donor kidney transplantation. Nephrology, dialysis, transplantation : official publication of the European Dialysis and Transplant Association - European Renal Association 2009, 24(4):1331-1334.

9. Radermacher J, Mengel M, Ellis S, Stuht S, Hiss M, Schwarz A, Eisenberger U, Burg M, Luft FC, Gwinner W et al: The renal arterial resistance index and renal allograft survival. N Engl J Med 2003, 349(2):115-124.

10. Heine GH, Gerhart MK, Ulrich C, Köhler H, Girndt M: Renal Doppler resistance indices are associated with systemic atherosclerosis in kidney transplant recipients. Kidney internationa/2005, 68(2):878885.

11. Krumme B, Grotz W, Kirste G, Schollmeyer P, Rump LC: Determinants of intrarenal Doppler indices in stable renal allografts. Journal of the American Society of Nephrology : JASN 1997, 8(5):813-816.

12. Frauchiger B, Schmid HP, Roedel C, Moosmann P, Staub D: Comparison of carotid arterial resistive indices with intima-media thickness as sonographic markers of atherosclerosis. Stroke; a journal of cerebral circulation 2001, 32(4):836-841.

13. Gerhart MK, Seiler S, Grün OS, Rogacev KS, Fliser D, Heine GH: Indices of systemic atherosclerosis are superior to ultrasound resistance indices for prediction of allograft survival. Nephrology, dialysis, transplantation : official publication of the European Dialysis and Transplant Association - European Renal Association 2010, 25(4):1294-1300.

14. Seibert FS, Behrendt C, Pagonas N, Bauer F, Kiziler F, Zidek W, Westhoff TH: Prediction of cardiovascular events after renal transplantation. Transplantation proceedings 2015, 47(2):388-393. 
15. Levey AS, Stevens LA, Schmid CH, Zhang YL, Castro AF, 3rd, Feldman HI, Kusek JW, Eggers P, Van Lente $\mathrm{F}$, Greene $\mathrm{T}$ et al: A new equation to estimate glomerular filtration rate. Annals of internal medicine 2009, 150(9):604-612.

16. Girometti R, Stocca T, Serena E, Granata A, Bertolotto M: Impact of contrast-enhanced ultrasound in patients with renal function impairment. World J Radio/ 2017, 9(1):10-16.

17. Mueller-Peltzer K, Negrão de Figueiredo G, Fischereder M, Habicht A, Rübenthaler J, Clevert DA: Vascular rejection in renal transplant: Diagnostic value of contrastenhanced ultrasound (CEUS) compared to biopsy. Clin Hemorheol Microcirc 2018, 69(1-2):77-82.

18. Thalhammer $C$, Aschwanden M, Mayr M, Staub D, Jaeger KA: Colour-coded duplex sonography after renal transplantation. Ultraschall in der Medizin (Stuttgart, Germany : 1980) 2007, 28(1):6-21; quiz 25.

19. Tublin ME, Bude RO, Platt JF: Review. The resistive index in renal Doppler sonography: where do we stand? AJR American journal of roentgenology 2003, 180(4):885-892.

20. Rifkin MD, Needleman L, Pasto ME, Kurtz AB, Foy PM, McGlynn E, Canino C, Baltarowich OH, Pennell RG, Goldberg BB: Evaluation of renal transplant rejection by duplex Doppler examination: value of the resistive index. AJR American journal of roentgenology 1987, 148(4):759-762.

21. Rigsby CM, Burns PN, Weltin GG, Chen B, Bia M, Taylor KJ: Doppler signal quantitation in renal allografts: comparison in normal and rejecting transplants, with pathologic correlation. Radiology 1987, 162(1 Pt 1):39-42.

22. Päivärinta J, Oikonen V, Räisänen-Sokolowski A, Tolvanen T, Löyttyniemi E, lida H, Nuutila $P$, Metsärinne K, Koivuviita $\mathrm{N}$ : Renal vascular resistance is increased in patients with kidney transplant. BMC nephrology 2019, 20(1):437.

23. Boran M, Boran E, Boran M, Tola M: Renal Doppler Resistance Indices in Kidney Transplant Recipients With Proteinuria. Transplantation proceedings 2018, 50(5):1355-1359.

24. Dupont PJ, Dooldeniya M, Cook T, Warrens AN: Role of duplex Doppler sonography in diagnosis of acute allograft dysfunction-time to stop measuring the resistive index? Transplant international : official journal of the European Society for Organ Transplantation 2003, 16(9):648-652.

25. Kramann R, Frank D, Brandenburg VM, Heussen N, Takahama J, Krüger T, Riehl J, Floege J: Prognostic impact of renal arterial resistance index upon renal allograft survival: the time point matters. Nephrology, dialysis, transplantation : official publication of the European Dialysis and Transplant Association - European Renal Association 2012, 27(10):3958-3963.

26. Gerhart MK, Seiler S, Grun OS, Rogacev KS, Fliser D, Heine GH: Indices of systemic atherosclerosis are superior to ultrasound resistance indices for prediction of allograft survival. Nephrology, dialysis, transplantation : official publication of the European Dialysis and Transplant Association - European Renal Association 2010, 25(4):1294-1300.

27. Di Nicolò P, Granata A: Renal Resistive Index: not only kidney. Clinical and experimental nephrology 2017, 21(3):359-366. 
28. Brennan DC, Lentine KL: Is there a correlation between atherosclerosis and renal resistive indices in kidney transplant recipients? Nature clinical practice Nephrology 2006, 2(2):64-65.

29. Bude RO, Rubin JM: Relationship between the resistive index and vascular compliance and resistance. Radiology 1999, 211(2):411-417.

30. Restrepo-Schäfer IK, Schwerk WB, Müller TF, Prinz H, Görg C, Arnold R: [Intrarenal doppler flow analysis in patients with kidney transplantation and stable transplant function]. Ultraschall in der Medizin (Stuttgart, Germany : 1980) 1999, 20(3):87-92.

\section{Figures}

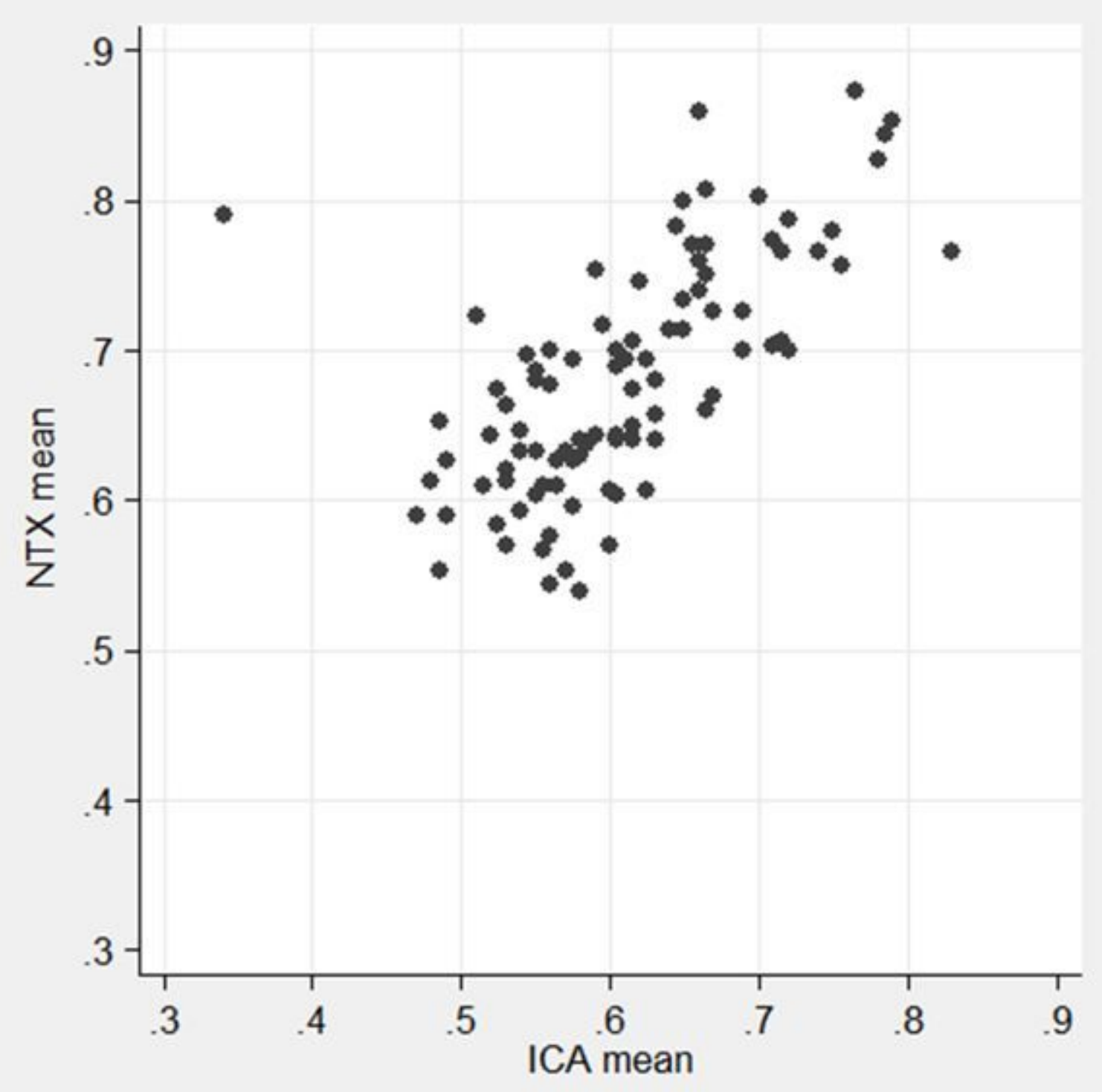

Figure 1 
Correlation of kidney transplant-RI and RI of the internal carotid artery Abbreviations: NTX: kidney transplant. ICA: Internal carotid artery. 